\title{
The role of medications misused for body weight gain on some fertility hormones concentration of female rabbits.
}

\author{
Adam Saba Siddig', Ahmed Adam Ismail2*, Babeker Awad Mohammed ${ }^{2}$ \\ ${ }^{1}$ Department of Chemistry, University of Kordofan, El-Obeid, Sudan \\ ${ }^{2}$ Department of Food Science and Technology, University of Kordofan, El-Obeid, Sudan
}

\begin{abstract}
The objective of the present work was to study the effects of some drugs misused by Sudanese women as body weight gain drugs on some fertility hormones concentration of female rabbits. Sixteen female rabbits were procured from local markets of Elnuhod localality, West Kordofan state. A randomized complete block design with three replicates was used; the treatments consisted of two drugs i.e., dexamethasone, cyperoheptadine and their combination administered orally with doses of $0.9 \mathrm{mg} / \mathrm{kg}$ of body weight with drugs two times a day for 45 days. Follicle stimulating hormone, luteinizing hormone, and prolactin were measured. The results showed that the medication used affects the levels of fertility hormones. The results showed that the level of FSH due to drugs decreased with time and the lowest level of the hormone was shown by the combination and dexamethasone and the values were $(2.32$ and $2.51 \mathrm{IU} / \mathrm{L}$, respectively), while cyperoheptadine recorded a level of $(2.75 \mathrm{IU} / \mathrm{L})$ as highest value with significant differences as compared to other two treatments. The results showed that prolactin hormone increased with time by all drugs used and their combinations at the end of the experiment period, and there was no significant difference between the drugs in their effect on hormone level, physician and pharmacist should be consultant before using these drugs to avoid the adverse effects is needed as recommended point of view, effects of drugs on serum total cholesterol, triglyceride, high-density lipo-protein, low density lipo- protein and very low density lipo- protein are also recommended for future work.
\end{abstract}

Keywords: Administered drugs, Fertility hormone, Female rabbits

\section{Introduction}

Dexamethasone used as treatment for certain types of cancers, autoimmune diseases as well as anti-inflammatory drug [1]. In Sudan Alnagma (Dexamethasone) is abused as cosmetic for gaining weight and whitening skin, without care of its side effects, doses and recommended storage conditions, so the drugs sells as illegal trade [2].

For many drugs, it is not known exactly what causes the weight gain. Some medications can increase appetite, cause fluid retention, or slowly lead to weight gain over a period of time due to fatigue and lower activity. Drugs that trigger increases in appetite may work in the brain and affect the satiety (fullness) center. It is often difficult to distinguish between weight gain from a drug and weight gain from other reasons, like diet or lack of exercise, because it can be a slow process. Weight gain may increase the chance for high cholesterol, hypertension (high blood pressure) and type II diabetes [3]. One of the most drugs misused by Sudanese women for body weight gain is Dexamethasone (locally knows as Alnagma) is for oral administration has many uses in the treatment of cancer. It is classified as a glucocorticosteroid [4].

Some side effects are common for patients whom administered dexamethasone increased appetite, irritability, difficulty sleeping (insomnia), swelling in ankles and feet (fluid retention) heartburn, muscle weakness, impaired wound healing and increased blood sugar levels and may others side effects with different level of occurrences [3]. Cyperoheptadine locally knows as peiractin, cyperoheptadine is an antihistaminic and antiserotonergic agent cyperoheptadine hydrochloride, is available for oral administration in $4 \mathrm{mg}$ tablets. Inactive ingredients include: lactose monohydrate, magnesium stearate, microcrystalline cellulose, and pregelatinized starch [4]. Dexamethasone people believed that it played a role in causing malignances, it may given at risk at delivering of premature in order to cause maturation of fetus lungs $[5,6]$. No detectable amounts of unchanged drug were present in the urine of patients on chronic 12 to $20 \mathrm{mg}$ daily doses. The principle metabolite found in human urine has been identified as a quaternary ammonium glucuronide conjugate of cyperoheptadine. Elimination is diminished in renal insufficiency [7], so the main objective of this study to know the effect of dexamethasone and cyperoheptadine drugs abused by Sudanese women for weight misused in female rabbits and their affects on some fertility hormones i.e., luteinizing hormone (LH), follicle stimulating hormone (FSH) and prolactin hormone (PRL).

\section{Material and Methods}

Drugs

Dexamethasone and cyperoheptadine tablets were procured from super market in Elobeid, North Kordofan State, Sudan. Each tablet was crashed $(0.9 \mathrm{mg})$ into powder and then mixed 
with $1 \mathrm{ml}$ of distilled water and kept as stock drug. Before use the stock suspension was homogenized sonicator and diluted to obtain appropriate doses concentration $(100 \mathrm{ml})$.

\section{Treatment}

Each rabbits group was treated with the prepared drugs as follows:

First group: No treatment (control).

Second group: Administration dexamethasone orally $(1.8 \mathrm{mg} /$ $\mathrm{kg}$ body weight).

Third group: Cyperoheptadine (1.8 mg/kg body weight).

Fourth group: Combined suspension $(1.8 \mathrm{mg} / \mathrm{kg})$.

\section{Experimental animals}

Sixteen female rabbits from local markets weighted 700-2000 grams were divided equally and randomly into four groups, Each group was kept in one cage, the animals were provided with composed of green carrot (Caucus carrot) as well as tap water free excess and maintained in air-conditioned quarters $\left(24^{\circ} \mathrm{C}\right)$ under standard husbandry conditions with alternate 12 hours light /dark period tell the end of experiment period (45 days).

\section{Collection of blood samples}

The blood samples were collected directly from the heart (cardiac puncture) in the first day and then every 15 days until the end of experimental period. Blood was collected in plastic tubes without anticoagulant and then refrigerated for 12 hour as maximum. Blood sample was centrifuged (5000 rpm) for 15 min to separate serum which was finally used for hormonal analysis (FSH, LH and PRL).

\section{Hormonal analysis}

Levels of fertility hormones (FSH, LH, PRL) were determined using Touché Hormones Apparatus' (moded) as per manual provided the manufacture.

\section{Statistical analysis}

In order to compare the effects of the treatments on the rabbit's fertility hormones, ANOVA were applied using complete randomized design (CRD) with help of computer program. Statistical packages for Social Science (SPSS V.19). Mean separation was done using the least significant differences (LSD), as described by [8] then the results were shown in means \pm SD.

\section{Results and Discussion}

\section{Effect of administered drugs on luteinizing hormone (LH) level (IU/L) of female rabbit}

Referring to comparison between groups, at first days there were no significant $(\mathrm{p} \leq 0.05)$ differences between dexamethasone, the combination of dexamethasone with cyperoheptadine in their effect on LH as compared with the control, while cyperoheptadine showed significant $(\mathrm{p} \leq 0.05)$ difference. At 15 days, 30 days and 45 days, cyperoheptadine showed significant ( $\mathrm{p} \leq 0.05$ ) difference as compared with dexamethasone and the combination of dexamethasone with cyperoheptadine. With regards to comparison with in the group at different time, the control showed no significant $(p \leq 0.05)$ differences between different periods of time. At 45 days Dexamethasone reported significant $(\mathrm{p} \leq 0.05)$ differences as compared with first days, 15 days and 30 days. At 15 days, 30 days and 45 days, the level of LH as affected by cyperoheptadine showed no significant $(\mathrm{p} \leq 0.05)$ differences between these periods of time, significant differences as compared with first day. At 15 days, 30 days and 45 days, the combination of dexamethasone with cyperoheptadine demonstrated no significant $(p \leq 0.05)$ difference in level of LH but at 30 days and 45 days there were significant $(\mathrm{p} \leq 0.05)$ differences as compared with first days. Generally, level of LH decreased with time and the lowest values of 2.37 and 2.49 were reported by the combination of dexamethasone with cyperoheptadine and dexamethasone, respectively, while cyperoheptadine showed the highest value of 2.78 at the end of the trial period. It can be concluded that the combination of dexamethasone with cyperoheptadine and dexamethasone the most drugs that decreased the level of $\mathrm{LH}$ which agreed with [9] and it was observed that dexamethasone reduced the level of LH by $0.17,0.13$ and 0.14 at 15 days, 30 days and 45days (Table 1).

\section{Effect of administered drugs on follicle stimulating hormone (FSH) level (IU/L) of female rabbits}

At first days, cyperoheptadine showed significant $(\mathrm{p} \leq$ 0.05) difference in its effect on FSH level as compared with the control, while dexamethasone and the combination of dexamethasone with cyperoheptadine showed no significant $(\mathrm{p} \leq$ 0.05 ) differences with the control. At 15 days, cyperoheptadine and the combination of dexamethasone with cyperoheptadine demonstrated significant $(\mathrm{p} \leq 0.05)$ differences as compared with each other and with dexamethasone and the control but dexamethasone showed no significant $(\mathrm{p} \leq 0.05)$ difference with the control. At 30 days, the combination of dexamethasone with cyperoheptadine showed significant $(\mathrm{p} \leq 0.05)$ difference in FSH level as compared with the control and cyperoheptadine, but showed no significant difference as compared with

Table 1. Effect of administered drugs on luteinizing hormone (LH) level (IU/L) of female rabbits.

\begin{tabular}{|c|c|c|c|}
\hline Treatments/periods & $\mathbf{0}$ day & $\mathbf{1 5}$ days & $\mathbf{4 5}$ days \\
\hline Control & $(2.65)^{\mathrm{Ba}} \pm 0.12$ & $(2.61)^{\mathrm{Aba}} \pm 0.05$ & $(2.63)^{\mathrm{Aba}} \pm 0.10$ \\
\hline Dexamethasone & $(2.78)^{\mathrm{Aba}} \pm 0.11$ & $(2.65)^{\mathrm{ABab}} \pm 0.09$ & $(2.56)^{\mathrm{ABab}} \pm 0.08$ \\
\hline Cyperoheptadine & $(2.90)^{\mathrm{Aa}} \pm 0.09$ & $(2.84)^{\mathrm{Aab}} \pm 0.06$ & $(2.49)^{\mathrm{BC}} \pm 0.08$ \\
\hline Dexa. and Cyper. & $(2.64)^{\mathrm{Ba}} \pm 0.05$ & $(2.51)^{\mathrm{Bab}} \pm 0.05$ & $(2.78)^{\mathrm{Ab}} \pm 0.06$ \\
\hline
\end{tabular}

*Each value is an average of three replicates and value is average \pm standard deviation. *Values in column share the same superscript capital letters show no significant difference between groups at 0.05 levels. *Values in Rows share the same superscript small letters show no significant difference within groups at 0.05 levels 
Table 2. Effect of administered drugs on follicle stimulating hormone (FSH) level (IU/L) of female rabbits.

\begin{tabular}{|c|c|c|c|}
\hline Treatments/periods & 0 day & 15 days & $\mathbf{3 0}$ days \\
\hline Control & $(2.61)^{\mathrm{Ba}} \pm 0.12$ & $(2.57)^{\mathrm{Bca}} \pm 0.05$ & $(2.62)^{\mathrm{Aba}} \pm 0.10$ \\
\hline Dexamethasone & $(2.75)^{\mathrm{Aba}} \pm 0.12$ & $(2.63)^{\mathrm{Bb}} \pm 0.08$ & $(2.62)^{\mathrm{Aba}} \pm 0.11$ \\
\hline Cyperoheptadine & $(2.90)^{\mathrm{Aa}} \pm 0.09$ & $(2.82)^{\mathrm{Aab}} \pm 0.08$ & $(2.51)^{\mathrm{Bcc}} \pm 0.09$ \\
\hline Dexa and Cyper & $(2.59)^{\mathrm{Ba}} \pm 0.03$ & $(2.45)^{\mathrm{Cb}} \pm 0.05$ & $(2.77)^{\mathrm{Aab}} \pm 0.06$ \\
\hline
\end{tabular}

*Each value is an average of three replicates and value is average \pm standard deviation. *Values in column share the same superscript capital letters show no significant difference between groups at 0.05 levels. *Values in rows share the same superscript small letters show no significant difference within groups at 0.05 levels

Table 3. Effect of administered drug on prolactin hormone (PRL) level (IU/L) of female rabbit.

\begin{tabular}{|c|c|c|c|c|}
\hline Treatments/periods & $\mathbf{0}$ day & $\mathbf{1 5}$ days & $\mathbf{3 0}$ days & $\mathbf{4 5}$ days \\
\hline Control & $(0.92)^{\mathrm{Aba}} \pm 0.19$ & $(0.99)^{\mathrm{Aa}} \pm 0.23$ & $(1.16)^{\mathrm{Aa}} \pm 0.33$ & $(1.03)^{\mathrm{Aa}} \pm 0.25$ \\
\hline Dexamethasone & $(0.86)^{\mathrm{Ba}} \pm 0.10$ & $(1.05)^{\mathrm{Ab}} \pm 0.89$ & $(1.32)^{\mathrm{Abc}} \pm 0.39$ & $(1.64)^{\mathrm{Ac}} \pm 1.23$ \\
\hline Cyperoheptadine & $(1.09)^{\mathrm{Aba}} \pm 0.21$ & $(1.25)^{\mathrm{Aab}} \pm 0.28$ & $(1.51)^{\mathrm{Ab}} \pm 0.25$ & $(1.73)^{\mathrm{Ab}} \pm 0.41$ \\
\hline Dexa and Cyper & $(1.39)^{\mathrm{Aa}} \pm 0.35$ & $(1.61)^{\mathrm{Aa}} \pm 0.31$ & $(1.61)^{\mathrm{Aa}} \pm 75.30$ & $(1.87)^{\mathrm{Aa}} \pm 0.55$ \\
\hline
\end{tabular}

*Each value is an average of three replicates and value is average \pm standard deviation. *Values in column share the same superscript capital letters show no significant difference between groups at 0.05 levels. *Values in rows share the same superscript small letters show no significant difference within groups at 0.05 levels

dexamethasone. At 45 days, the combination of dexamethasone with cyperoheptadine showed significant $(\mathrm{p} \leq 0.05)$ differences compared with the control and cyperoheptadine, but it showed no significant $(p \leq 0.05)$ difference as compared with dexamethasone. In case of comparisons within the group, the control revealed no significant $(\mathrm{p} \leq 0.05)$ differences throughout the period of the experiment. Dexamethasone at 30 , and 45 days recorded significant $(\mathrm{p} \leq 0.05)$ differences as compared with 0 days and with 15 days. Cyperoheptadine showed no significant $(p \leq 0.05)$ differences between 15, 30 and 45 days. In case of the combination of dexamethasone and cyperoheptadine, 45 days showed significant $(p \leq 0.05)$ differences as compared with first day and 15 days (Table 2).

The results showed that the level of FSH due to treatments decreased with time and the lowest level of the hormone was recorded by the combination of dexamethasone with cyperoheptadine and dexamethasone which agreed with [9] and the values were 2.32 and 2.51, respectively and it was found that dexamethasone reduced the level of FSH by 0.19 , 0.14 and 0.20 during times 15,30 and 45 days in sequentially, while cyperoheptadine recorded a level of 2.75 as highest value as compared with the control, dexamethasone and the combination of dexamethasone with cyperoheptadine, moreover, Cyperoheptadine even at 0 time recorded hormone level of 2.90 which is considered as the greatest value among other treatments.

\section{Effect of administered drug on prolactin hormone (PRL) level (IU/L) of female rabbits}

In case of comparison between treatments at first days, there was significant $(p \leq 0.05)$ difference between dexamethasone and the combination of dexamethasone with cyperoheptadine in their effect on PRL hormone, but there were no significant $(p \leq 0.05)$ differences between each drug as compared with the control between 15,30 and 45 days no significant ( $\mathrm{p} \leq$ 0.05 ) differences were recorded between all treatments. In case of comparisons within the group, the control showed no significant $(\mathrm{p} \leq 0.05)$ differences in hormone level throughout the experimental period ( $0-45$ days). There were significant ( $\mathrm{p} \leq$
0.05 ) differences reported by dexamethasone between 15,30 and 45 days as compared with first days first days, but no significant $(p \leq 0.05)$ differences were demonstrated between 15 days and 30 days and between 30 days and 45 days. Cyperoheptadine reported significant $(p \leq 0.05)$ differences when comparing the level of hormone at 30 , and 45 days with the level at first days, but no significant $(p \leq 0.05)$ differences were revealed when comparing the level of hormone at 15 days and at first days, 30 days and 45 days. The combination of dexamethasone and cyperoheptadine demonstrated no significant $(\mathrm{p} \leq 0.05)$ differences throughout the period of experiment from first days up to 45 days (Table 3 ).

It was observed that the level of PRL was increased with time and the highest level was 1.87 and it was reported by $(\mathrm{p} \leq 0.05)(\mathrm{p}$ $\leq 0.05)$ the combination of dexamethasone and cyperoheptadine followed by cyperoheptadine (1.73), dexamethasone (1.64), and the control (1.03). The results showed that dexamethasone increased the hormone level by $0.47,0.23$ and 0.84 at 15,30 and 45 days, respectively.

\section{Conclusion}

The present study concluded that dexamethasone and the combination of dexamethasone with cyperoheptadine drugs decrease the level of luteinizing hormone. The lowest level of the Follicle stimulating hormone was reported by dexamethasone and the combination of dexamethasone with cyperoheptadine. The combination of dexamethasone and cyperoheptadine followed by cyperoheptadine and then dexamethasone were found to increase prolactin hormone level.

\section{Recommendations}

More elaborated work concerning weight-gaining drugs should be carried-out considering longer experimental period as well as larger sample size of different laboratory animals. Other body weight increasing drugs such as prednisone, Beta Blockers, Insulin and Anti-depressants and body weight loss drugs as hydroxycut, Caffeine and orlistat need to be investigated in future work. Physician and pharmacist consultation before using these drugs to avoid the adverse effects is needed as recommended point of view. 
Citation: Siddig AS, Ismail AA, Mohammed BA. The role of medications misused for body weight gain on some fertility hormones concentration of female rabbits. J Food Sci Nutr. 2018;1(1):13-16.

\section{Acknowledgments}

The authors appreciated the help given by the staff of central veterinary laboratory, Elobeid, Department of chemistry faculty of education; the help given by the dean faculty of natural resources and environmental studies is also appreciated.

\section{Conflicts of Interest}

The authors declared that no conflicts of interest for this article.

\section{Ethical Permission}

Ethical permission was taken from the wildlife authority department action no (52/5/A/6M).

\section{Reference}

1. Gonzalez R, Ruiz-leon Y, Gomendio M, et al. The effects of glucocorticoids on mouse oocyte in vitro maturation and subsequent fertilization and embryo development. Toxicol In Vitro. 2010;24:108-15.

2. Amar MI, Adam Shama IY, Enaia AA, et al. Effects of various levels of oral doses dexamethasone (Al-nagma) abused as cosmetic by Sudanese women on Wistar rats. J Med Sci. 2013;13:432-438.
3. Pagana KD, Pagana TJ. Mosby's Manual of Diagnostic and Laboratory Tests (4th edn.). Mosby Elsevier, St. Louis. 2010.

4. De Wasch K, De Brabander HF, Van De Wiele M, et al. Differentiation between dexamethasone and betamethasone in a mixture using multiple mass spectrometry. J Chromatogr A. 2001;926:79-86.

5. Siddigui E, Qazi GI. Role of dexamethasone in meningitis. In: Wireko BG (ed.). Meningitis. Intech, USA.

6. Bloom SL, Sheffield JS, McIntire DD, et al. Antenatal dexamethasone and decreased birth weight. Obstet Gynecol. 2001;97:485-90.

7. Welsh AL, Ede M. Studies of cyperoheptadine combined with dexamethasone. J Clin Pharmacol. 2013;2:223-31.

8. Sendecor GW, Cochran WC. Statistical method (8th edn.). Iowa State University Press, Iowa. 1989.

9. Rashad FG, Ala AL-deen HJ. Effects of dexamethasone, estrogen administration on leptin, thyroid, reproductive hormone concentration and lipid profile of female rabbits serum. Basrah Journal of Veterinary Research. 2013;12:41-53.

\section{*Correspondence to:}

Ahmed Adam Ismail

Department of Food Science and Technology University of Kordofan

Elobeid

Sudan

Tel: 00249122245279

E-mail: adamalgnana62@yahoo.com 